\title{
"The First Day He Kicked Shoes at Me, the Last Day He Brought Me a Picture of Himself": Investigating the Practicum Experiences of Pre-service Teachers
}

\author{
Gabrielle Young \\ Memorial University of Newfoundland \\ Jacqueline A. Specht, Fiona E. Hunter \\ University of Western Ontario \\ Sarah Terreberry \\ Brock University \\ Donna McGhie-Richmond \\ University of Victoria \\ Nancy L. Hutchinson \\ Queen's University
}

\begin{abstract}
The purpose of this study was to describe the ways in which the experiences gained during practica influence the developing self-efficacy of Canadian pre-service teachers for teaching in inclusive classrooms. Questionnaires were issued to participants in teacher education programs at 11 universities across Canada, and the data were subjected to content analysis. Several themes that emerged from the participant responses were found to be influential in pre-service teachers' feelings of efficacy, with behaviour management having the greatest influence, regardless of whether participants felt successful or challenged. Academic outcomes, relationships with students, and other school adults as resources were also identified as themes influencing pre-service teachers' feelings of success and challenge in practica. The data revealed attitudes and beliefs about inclusion and the impact these may have on teacher efficacy. Several elements can positively influence teacher efficacy including the ability to identify and utilize instructional and personnel resources, the ability to form supportive professional relationships with other school
\end{abstract}


adults, and the ability to recognize achievement as it pertains to the individual rather than prescribed norms. As beliefs about self-efficacy are informed by enactive mastery experiences, vicarious experiences, physiological factors, and verbal persuasion, teacher preparation programs can foster teacher efficacy by encouraging the development of positive attitudes and equipping teachers with the skills they need.

Inclusion is "based on the assertion of the same right to a quality education within their communities for all learners" (UNESCO, 1999, p. 21). Since the issuance of the Salamanca Statement (UNESCO, 1994), governments globally have increasingly focused on the development of inclusive education systems. As a result of this growing commitment to inclusion, classroom populations are becoming increasingly diverse. It is incumbent on institutions of higher learning to understand and equip those who intend to teach in these classrooms with the skills and knowledge necessary to meet the demands of today's diverse classrooms. To ensure future educators are efficacious, inclusive practitioners, it is vital to understand the myriad influences that may act as facilitators or barriers to inclusive practice.

The discourse on inclusive schooling has resulted in the emergence of several separate but interlinked elements that can either facilitate or serve as barriers to inclusion. Some of the main issues emerging from the research include leadership and organization (Ainscow, 2005; Ainscow \& Sandill, 2010; Edmunds, Macmillan, Specht, Nowicki, \& Edmunds, 2009), classroom management and instructional strategies (Polirstok, 2015; Savage, 2006; Schmidt, Rozendal, \& Greenman, 2002), and attitudes and beliefs (Bunch, Lupart, \& Brown, 1997; Loreman, Sharma, \& Forlin, 2013). There is growing evidence that schools can be both effective and inclusive (McLeskey, Waldron, Spooner, \& Algozzine, 2014). Several authors have identified key characteristics of effective inclusive schools, ensuring that the discourse surrounding inclusion is moving from why schools should be inclusive to how to make them so (Loreman, 2007). These debates serve to illustrate both the complexity of concerns relating to inclusion and the differing perspectives about inclusion, which may serve to influence the beliefs and subsequent attitudes individuals may hold about the ethos of inclusion.

Teachers have been described as having a pivotal role in realizing the goal of inclusion (McGhie-Richmond, Irvine, Loreman, Cizman, \& Lupart, 2013). Several studies have found that positive teacher attitudes toward inclusion can be the most influential factor in the development of inclusive schools and classrooms (Jordan \& Stanovich, 2003; Sharma, Forlin, \& Loreman, 2008; Stanovich \& Jordan, 2004). It has also been shown that resistance to inclusion is one of the biggest barriers to creating inclusive school environments (Avramidis \& Norwich, 2002; Brighton, 2003; McGhieRichmond et al., 2013). The ethos and ecology of a school have been shown to directly influence how effectively inclusive it is (Farrell, Dyson, Polat, Hutcheson, \& Gallannaugh, 2007). Professionals with whom pre-service teachers interact and observe, together with the communities in which many will gain their first authentic teaching experiences, influence the development of their beliefs and, in turn, their future classroom behaviour. 


\section{Attitudes and Beliefs}

The theoretical histories of attitudes and beliefs are strongly intertwined. In a seminal paper Richardson (1996) noted that both are extremely important in the development of teachers. Beliefs refers to psychologically held understandings, premises, or propositions that are felt to be true and accepted as a guide for assessing the future, whereas attitudes refers to responding in a favourable or unfavourable way through actions or words based on those beliefs (Richardson, 1996). These constructs are important to study, as they play a large role in how teachers learn to teach. Beliefs are developed through personal experience, the learner's own schooling, and formal knowledge. Teacher education programs, then, are pivotal in continuing to shape the beliefs and attitudes of our future teachers. If pre-service teachers leave teacher preparation programs with negative attitudes toward inclusion, it can be very difficult to change these attitudes over the course of their careers (Hoy \& Spero, 2005). Continuing professional development is needed to address beliefs and attitudes surrounding inclusion (McLeskey \& Waldron, 2002) and to challenge those that are not conducive to inclusive practices. Pre-service programs should encourage individuals to consider their personal philosophies with regard to inclusion (Loreman, 2007), as attitudes about disability may be indicative of a wider set of beliefs (Jordan, Schwartz, \& McGhie-Richmond, 2009). Research has found that the attitudes of some pre-service teachers are not in keeping with inclusive principles (Sharma, Forlin, Loreman, \& Earle, 2006); however, teacher preparation programs are in a unique position to address such concerns by encouraging the development of positive attitudes and equipping teachers with the skills they need (Sharma et al., 2006). Attitudinal issues remain a well documented barrier to inclusion.

\section{Teacher Efficacy}

Given that one of the major contributory factors to positive attitudes is the confidence in oneself to be able to meet the challenge of diversity in the classroom, it is necessary to consider what the research reveals regarding teacher efficacy. Self-efficacy is the beliefs one holds about one's personal capabilities (Bandura, 1977), whereas teacher efficacy refers to the beliefs one holds about whether one can meet the needs of all learners within the classroom (Hoy \& Spero, 2005). Teacher efficacy has been shown to influence teacher professional commitment (Klassen et al., 2013), resilience (Bobek, 2009), teacher performance and student achievement (Caprara, Barbaranelli, Steca, \& Malone, 2006; Klassen \& Durksen, 2014), and job satisfaction (Høigaard, Giske, \& Sundsli, 2012). It has also been shown that efficacy can influence classroom behaviours, particularly with regard to learners with additional needs (Palmer, 2006). It is apparent that much of the research regarding teacher efficacy to date has focused on those who are qualified and working within the field. Much less research exists on those factors that are influential in the development of efficacy in pre-service teachers, and in particular how practica experiences impact developing teacher efficacy (Specht et al., 2016). Pre-service teachers were surveyed about their confidence, concerns, and efficacy for inclusive classroom teaching before and after a course on inclusive education (Sokal, Woloshyn, \& Funk-Unrau, 2013). Students who experienced a practicum in an inclusive setting developed greater teacher efficacy in classroom management than those students with no practicum (Sokal et al., 2013). However, research by Forlin and Chambers (2011) found 
that as pre-service teachers developed more teacher efficacy for inclusive settings, they also developed higher levels of concerns; and the more they learned about and experienced inclusive practices within the current system, the higher their levels of concern became. These findings support the importance of high quality inclusive practica as an essential feature of effective inclusive teacher preparation programs. As research confirms that teacher efficacy is crucial, not only for the well-being of the individual, but also in relation to their classroom behaviours and student outcomes, it is of paramount importance to gain a greater understanding of how efficacy develops.

According to Bandura (1977), beliefs about self-efficacy are informed by four main sources: enactive mastery experiences, vicarious experiences, physiological factors, and verbal persuasion. Therefore, practicum experiences could be crucial for pre-service teachers, as the process involves watching others, developing and practising new techniques, and engaging in dialogue with students and school personnel. Research has shown that while pre-service teacher efficacy can increase during course work, it often decreases during practicum (Woolfolk Hoy \& Burke-Spero, 2005). A better understanding of the perceptions of pre-service teachers of their performance within inclusive classrooms, the performance of others they see modelled, and the feedback they receive, may allow further tailoring of initial teacher education to ensure these experiences are positive.

One of the most cited concerns regarding inclusion is that teachers feel ill-prepared to meet the needs of the students they encounter (Kosko \& Wilkins, 2009; Smith \& Tyler, 2011). Teachers report feeling overwhelmed by the diversity of student needs in their classrooms (Bryant, Linan-Thompson, Ugel, Hamff, \& Hougen, 2001), and feel they lack training in strategies to meet these needs (Kosko \& Wilkins, 2009). In examining Canadian teachers' perceived stressors in inclusive classrooms, factors that indicated high levels of stress for teachers were perceptions of self-efficacy, professional training, and student behaviours (Brackenreed, 2008). While preparation program content can help alleviate these concerns, it is impractical to assume teacher preparation courses can ensure that every participant believes they are equipped to deal with every instance of diversity they may encounter. Content should be designed to develop a set of skills that will increase teacher efficacy rather than solely focusing on developing an understanding of specific disabilities or needs, as beliefs about self-efficacy are informed by mastery experiences (Bandura, 1977). Courses that develop both content knowledge and pedagogical knowledge have been shown to increase teacher efficacy and attitudes toward inclusive schooling (Kim, 2011; Sharma et al., 2008). Developing teachers who view their students holistically and are equipped with a range of strategies to support diverse needs is essential to promoting inclusive schools and improving student outcomes.

\section{Practicum Experiences}

While most studies have found that teacher preparation programs do not change firmly held beliefs of pre-service teachers, those with high-quality practica rooted in collaboration between university and school can be successful at impacting beliefs (Forlin \& Chambers, 2011; O'Toole \& Burke, 2013). Intrinsically interwoven into the concepts of practica and professional collaboration are the classroom teachers who play a 
vital role in the pre-service teachers' experiences. However, there remains a paucity of research on this crucial aspect of teacher education.

Providing pre-service teachers with the opportunity to identify their most serious challenge and supporting them to find and implement strategies to meet that challenge can have a positive impact on their self-efficacy (Sharma et al., 2008). To ensure future educators are efficacious, inclusive practitioners, it is vital to understand the many influences that may act as facilitators or barriers. If educators can understand the mechanisms within practica that influence pre-service teachers, and can develop ways to mitigate the more negative influences, this can serve to develop teachers who are better equipped and who believe that they can be inclusive educators (i.e., highly efficacious).

This qualitative study examined self-reported experiences during practica that engendered feelings of success or challenge in pre-service teachers attending universitybased institutions across Canada. These descriptions of success and challenge situations serve to illustrate commonalities among the experiences gained. As the descriptions were self-reported, it is possible to identify individual efficacy beliefs along with commonalities among more broadly held attitudes and beliefs about inclusive classrooms.

\section{Methods}

\section{Participants}

Participants consisted of 1,490 pre-service teachers participating in university-based education programs in 11 faculties at various Canadian locations. Programs of initial teacher education in Canada vary, but typically students achieve an undergraduate degree of 3 to 4 years in an area of specialty and then enter a teacher education program of 1 to 2 years in which they learn the pedagogical practices. In some universities, there are Bachelor of Education programs that students enter from secondary school and are 5 to 6 years duration, with the speciality areas and pedagogy intermixed over these years.

Participants were broadly recruited from across Canada, and ranged from 20 to 56 years of age, with a mean age of $25.9(S D=5.4)$, and the sample was composed of $74.2 \%$ female and $25.8 \%$ male participants.

\section{Procedures}

Distribution of the questionnaire took place during one of the final classes concerning special and inclusive education, which formed part of the pre-service teachers' university course work. Information regarding the procedures and goals of the research was read to potential participants, and survey packs were then distributed. The focus of the current analysis was two questions specifically relating to practicum experiences:

Give one example of a situation in which you felt particularly successful in meeting the needs of a student with an exceptionality while on your practicum. Explain why you felt successful. What resources did you use to help you determine how to meet the needs?

and: 
Give one example of a situation in which you faced particular challenges in meeting the needs of a student with an exceptionality while on your practicum. Explain why you found it challenging. What resources did you use in trying to work through the situation?

By requesting descriptive responses and soliciting additional information, we sought to gain insight into the lived practicum experiences of pre-service teachers and to gain a greater understanding of the impact, if any, these experiences have on the development of beliefs, attitudes, and teacher efficacy regarding inclusion.

\section{Analyses}

Qualitative thematic analysis (Braun \& Clarke, 2006) comprising six phases (familiarization with data, generation of initial codes, searching for themes, reviewing themes, defining and naming of themes, and production of the final report) was utilized in the current study. Given the complexity of the elements involved, a coding system evolved that comprised codes for the main elements identified in the responses, followed by sub-codes identifying relevant secondary information and, where necessary, further codes identifying pertinent information relating to either the primary individual or to the grade or subject area. Inter-coder reliability was improved by having two researchers code independently (Neuendorf, 2002). This resulted in over $80 \%$ agreement, which has been found to be acceptable in content analysis (Neuendorf, 2002). When coding of the data was completed and the primary themes identified, further review of the data was undertaken to identify any latent themes that existed within the statements of participants and to elicit those statements that richly describe the experiences of pre-service teachers.

\section{Results}

The analyses of the data revealed the emergence of several main themes in response to both questions. The following themes emerged whether participants were describing situations in which they felt successful or situations in which they felt challenged: behaviour management, academics, relationships with students, and relationships with other school adults. Feelings of success among pre-service teachers are discussed first, followed by what makes them feel challenged.

\section{What Makes Pre-service Teachers Feel Successful?}

Behaviour management. One of the most commonly identified successful outcomes for students was increased engagement and participation. The ways in which pre-service teachers achieved improvements in student engagement were complex; however, a recurring theme was behaviour management. Participants reported that the times when they felt they had provided students with the skills and support needed to successfully manage their behaviour made them feel successful. There were some distinct differences in the ways in which improving student outcomes through behaviour management was achieved. Some pre-service teachers implemented specific strategies to provide support, including the use of fidget balls and kinaesthetic strategies. One participant's comment is illustrative: 
I felt I was successful meeting the needs of two ADD students by seating them near the front, checking for understanding, reducing their work volume, and allowing them to take a quick walk if they were restless. This was successful because it helped them deal with the challenges of their exceptionality (restlessness, distracted), yet still work at the same level of complexity as their peers.

The responses revealed that pre-service teachers felt successful when they were able to establish behaviour management techniques that supported the needs of their students. They could identify successful outcomes, such as supporting students in regulating their behaviour, that may appear unrelated to academic success but that will ultimately support the student throughout their academic career.

Academics. In comparison with behaviour management, a relatively small number of descriptions relate directly to academic success. One participant described the following:

I gave a student with a learning disability the choice of writing their test in a resource room or in the class. This markedly improved their test scores, as they were less distracted. I felt successful, as this helped the student to pass the course.

One pre-service teacher reported that the need for accommodation extends beyond in-class differentiation, and identified a strategy to meet that need: "One of my students had a very difficult home life. She and I devised a plan where she could always make up for late assignments and tests. Her grade improved drastically as the term progressed." These statements clearly describe pre-service teachers who care for the well-being of their students as well as their academic achievement, and who are also able to recognize that well-being and achievement are intrinsically linked.

Relationships. Several responses from participants indicated that they understood the need to support student well-being and that one of the primary ways to do so was through the development of positive student-teacher relationships:

I had three LD students in one class. I took the time to get to know them and their interests. Over time I noticed them making a much stronger effort in the class, and they would stop me in the halls to discuss the lessons. As a result, their grades improved significantly.

For other participants, it is clear that developing a relationship is an important element in the management of student behaviours:

I spent a lot of time working with a student with behavioural issues. The first day he kicked shoes at me. The last day he brought me a picture of himself. By building a relationship with him, he was able to trust me. He could co-operate with me and would complete the work with help through non-traditional methods-computer, visual.

Other school adults as resources. Participants were asked to provide details of the resources used to meet students' needs. Several resources were identified that were utilized by pre-service teachers and contributed to their feelings of success. While some responses identified specific programs or equipment, the majority related to the use of other professionals within their practicum placements.

The classroom teacher was cited as a commonly used resource: 
I felt successful meeting the needs of a student on an IEP when I had the guidance of my classroom teacher. She had established a routine with the IEP student based on accommodations and modifications. When I began to teach the Grade 5 class I followed her routine and saw firsthand how I could include all students in their classroom.

Educational assistants (EAs) were one of the most commonly cited school adults that respondents utilized. Many described incidents in which they had spoken with the EA to gain a better understanding of the student, insight into their interests, or specific strategies that were known to be successful in supporting their learning:

I felt successful in meeting the needs of a student with autism by working with [the EA] to tailor projects to make them meaningful and relevant to him. Having the support of [the EA] was extremely valuable in forming learning opportunities that met his needs.

Participants reported using learning resource teachers together with teachers from other classes and, on occasion, senior school staff such as the principal as sources for specific strategies or resources or in the wider context of accumulating additional knowledge and information.

Summary. Pre-service teachers in this study felt successful when they could connect with their students and witness positive outcomes as a result of this connection. Positive outcomes were perceived in light of meeting the students' needs, and not merely improvements in grades or other forms of standardized assessment. The ways in which these outcomes were achieved were as individual as the students themselves; however, behaviour management was a frequently occurring theme. It is apparent from the data that when pre-service teachers felt able to identify and provide appropriate support to enable students to manage their behaviour, this directly impacted their feelings of personal success. This was also true when they increased student engagement. Preservice teachers having familiarity with a range of strategies to support students and the ability to identify the need for, and sources of, additional support were crucial in ensuring student success and, consequently, feelings of personal success. Upon addressing elements that contribute to feelings of success in pre-service teachers, the sections that follow consider the data relating to situations in which respondents felt challenged.

\section{What Makes Pre-service Teachers Feel Challenged?}

Behaviour management. Behaviour management was a prominent theme related to challenges experienced by pre-service teachers, especially with regard to aggressive behaviours:

Behavioural problems scare me. These kids can be very aggressive, and I don't know what the best way to respond is, and there is a lot of "physical" stuff involved. Physical anger, tears, shouting; during instruction time this is really hard, as the class is interrupted and the problem has to be handled. Co-operating teacher helped both times.

The feeling of making little or no progress was echoed in other responses: "I feel challenges when working with aggressive students. I do not have the skills or knowledge to help them." 
Within the previous response there is a suggestion that the pre-service teacher not only felt challenged, but also felt that they had somehow failed. This was not always the case, as is demonstrated in the following response:

I had a student who was very inattentive and aggressive. Every day was a challenge trying not to come off [task] to address his behaviour. I offered him a lot of extra assistance inside and outside the classroom. By the end of my internship he did settle down a little.

What is of particular interest in this response is that the behaviour was not described as the challenge, but rather the participant's response to it. The participant described the strategies they utilized, which may explain the more positive conclusion to their description.

Aggressive behaviour was not the only concern among the participants. Many reported feeling challenged by out-of-seat behaviour and students who had difficulty maintaining focus. Participants also described challenges when dealing with students who demonstrated difficulties regulating their emotions. Behavioural challenges can leave the pre-service teacher feeling they have not managed the situation well or that there is something else they should have done. This type of response is indicative of practitioners who are deeply invested in meeting the needs of all their students and of reflective practitioners who look to their own behaviours in the classroom to deal with the challenges they meet. They show concern for all of their students and for the ways in which students may be affected by challenging behaviours.

Academics. Pre-service teachers were concerned with their ability to manage behaviour in the classroom, and to ensure that their students were engaged and learning. At times this desire was hindered by actual or perceived lack of the necessary strategies or expertise to ensure student engagement. One participant noted, "There were numerous times I felt that I only learned the basics in my exceptionalities course, and I was always asking other teachers and trying to figure out what to do. I didn't feel confident at all." These concerns were also apparent when supporting gifted students, as pre-service teachers often felt they did not have the necessary knowledge to extend the learning of these students in a meaningful way:

I find it difficult to authentically challenge gifted students. I don't want to give them more of the same, or ask them to help struggling students, but it is easy to "ignore" them because they often do everything you ask without complaint or trouble. I try to use effective questioning to challenge them.

In some responses, the pre-service teachers described trying multiple strategies that did not appear to have had the desired effect, and reported feeling that they had somehow failed or should have done more. The results revealed that pre-service teachers often felt frustrated when they were unable to meet the needs of their students. For some this frustration stemmed from feelings that they were ill-equipped to meet the challenges they faced. For others this frustration came as a result of putting a strategy in place and not having the resources to implement it:

The student had already failed the credit twice and refused to do anything. I convinced him to do work if it was on a computer, but then I was unable to get access to a computer for him, and he stopped coming altogether after that. 
It may have been a result of these frustrations, or the sense of having failed in some way, that led some of the respondents to make statements regarding the appropriateness of placement for some students:

I found it very difficult to communicate with a student with autism. She often did not answer my questions, and I had a student with un-medicated ADHD [attentiondeficit/hyperactivity disorder] who had a very hard time sitting down for more than a few minutes. This student was very disruptive to the learning of others, and I believe should not be in a regular classroom. However, I gave him a corner at the desk with a computer where he was able to play an educational game to help with his focus.

Relationships. Pre-service teachers described challenging situations in which they endeavoured to form and maintain meaningful relationships with their students, some of which were more successful than others: "It was very challenging in the beginning, as most of my students, and in particular, three with learning disabilities, believed they had nothing to offer to the assignments. Through encouragement and the development of relationships, this began to change." Developing positive student-teacher relationships to support classroom management was much more apparent in the descriptions of success than challenge. Those pre-service teachers who could form positive relationships appear to have had many more experiences of success.

Other school adults as resources. The role of other school adults differed significantly in descriptions of challenging situations compared to those of success. When pre-service teachers felt the classroom teachers perceived a student as "beyond help," or when staff appeared unable or unwilling to offer support, this directly impacted their own behaviours, either positively or negatively:

There was a student who had ADD [attention-deficit disorder]. My associate [teacher] was not particularly helpful in addressing the situation. I tried to keep the student on task during seatwork by encouraging and refocusing him on his work, but I was unable to provide any strategies or tips for him. My AT [associate teacher] just saw him as a problem and didn't take an active approach in assisting him to stay on task. Because of this, there was very little I was able to do.

This participant further described their experience as a whole-school issue:

Disagreement in removal policy; strategies involved punishing consequences instead of helping student. Difficulty was with school's plan of action. Claim to be inclusive, but student was "disrespectful" to staff. Behaviours were taken personally.

When feeling challenged, many participants described positive interactions and much support from the school staff they communicated with:

I had a student in my class who was incredibly gifted, and I found I had to challenge her in meaningful ways without giving her more work than the other students. I used my cooperating teacher as a resource in this situation, and she gave me great ideas of ways to work around this type of challenge.

Summary. Not all circumstances in which pre-service teachers feel challenged have negative or unsuccessful outcomes; it is the situation itself that engenders a feeling of challenge. The situations surrounding the management of behaviour were commonly featured in the responses relating to challenging situations. As with all of the themes that 
describe situations regarded as challenging, the specific circumstances themselves and even the outcomes are not necessarily negative; however, when they were, the described impacts were at times profound.

\section{Discussion}

This study examined responses relating to practicum experiences in order to describe specific elements that influenced the development of efficacy in Canadian pre-service teachers. Four themes were identified in the results. The data revealed situations that were often complex and the result of more than one factor. Descriptions of success were evident, particularly in relation to behaviour management and strategies for engaging students. These findings, and those relating to each theme are discussed in greater detail.

\section{Behaviour Management}

Of the recurring themes within the data, behaviour management was one of the most cited in relation to success and challenge situations. This is not surprising considering that unwanted student behaviours have been frequently cited as a perceived barrier to inclusion in the general education classroom and a cause for concern among teachers (Avramidis \& Norwich, 2002; de Boer, Pijl, \& Minnaert, 2010). Responses in the current study highlighted that behaviour management directly influenced feelings of efficacy both positively and negatively. In instances when behaviour was managed effectively using specific strategies or the pre-service teachers' own problem-solving skills, they reported feelings of success. However, in those circumstances in which behaviour management did not appear to have the desired result, in which pre-service teachers felt overwhelmed, or in which additional support was required from other school adults, many participants expressed feeling unsuccessful. In these circumstances, pre-service teachers often directed these feelings of failure at themselves, describing how they felt they "should have done more." In many instances, situations in which the participant felt unsuccessful led to personalized perceptions of failure. In contrast, successes were often linked with successful student outcomes, increased engagement, and/or improved academic outcomes. This distinct contrast in the attribution of success and failure may be overstated, given that descriptions were limited to questionnaire responses. Nevertheless, the contrast is striking and warrants further consideration. From this data set it is not possible to ascertain all of the elements influential in making pre-service teachers feel they have failed. However, it is reasonable to posit that these feelings may arise from personally held constructs (Jordan et al., 2009), not having the knowledge of appropriate strategies or the skills to employ them effectively (Forlin, Keen, \& Barrett, 2008), or an inconsistency between their expectations and reality (Friedman, 2000).

Many reported situations in which pre-service teachers faced challenging behaviours in the classroom that did not result in negative outcomes. This became apparent when comparing those situations reported as success or challenge. Often participants described very similar situations resulting in similar outcomes, but some pre-service teachers perceived the situations as successes, while others regarded them as challenges. Within descriptions of challenging situations, similar situations were perceived differently, with some participants describing situations in which they persevered with different strategies 
and felt they did ultimately have some success, and others simply reporting that they "tried everything" but "nothing worked." These descriptions contained greatly nuanced understandings of success and challenge. Teacher efficacy may offer one explanation; some people view a challenge positively and use it as motivation for personal growth, while others may not have the self-efficacy to believe they can surmount the challenge. Or personal beliefs about inclusive classrooms may be a factor, as teachers' negative attitudes toward inclusion are some of the greatest barriers to inclusive practice (Jordan et al., 2009). Some pre-service teachers may see behaviour challenges as a normal or expected characteristic of a diverse classroom and may have the belief that, as a teacher, it is their responsibility to meet the needs of all learners to the best of their ability, regardless of whether that need is social, emotional, or academic (Specht et al., 2016). Others may hold the belief that their role is to teach subject matter and that managing behaviours is a distraction. Some respondents revealed concern about time spent managing behaviour that was not spent teaching. Such comments reveal a narrow understanding of what it means to teach. It is apparent from such comments that teaching is narrowly defined within the framework of curriculum content, perhaps, with limited conceptualization of role and importance of how to learn. As Hallam (2009) argued, it is as incumbent upon teachers to equip children with skills such as emotion regulation, which will support them throughout their lives, as it is to teach them academic content. It is imperative that teachers enter the profession understanding the demands of diverse classrooms and leave feeling equipped to meet these demands, as teachers who feel unable to meet the challenges of diversity will be less committed to developing and sustaining inclusive classrooms (Glazzard, 2011). Friedman (2000) used the term professional efficacy discrepancy to explain the difference in an individual's expectation of their professional abilities and professional experiences and the actual lived reality. When designing programs to meet the needs of beginning teachers, teacher preparation programs may need to consider ways to highlight the role and mediate the effects of professional efficacy discrepancy and to ensure that teachers enter the profession with an expectation to teach all children.

\section{Academics}

Descriptions relating to academic circumstances were featured in many of the responses pertaining to both challenges and successes. Identifying specific elements relating to teacher efficacy and student outcomes was not a simple endeavour. Concerns regarding, or success in supporting, academic outcomes were closely intertwined with other elements such as behaviour management or forming a relationship with the student. Responses in both success and challenge situations described similar circumstances; however, as with behaviour management, the perception of the pre-service teacher impacted whether these instances were considered successes or challenges. This attribution appeared to be based on their perceptions of what constitutes academic success and whether this pertains to specific students or the entire class. It is the teachers' role to support the whole child, and this includes supporting individual students as they learn to regulate their academic, social, emotional, and behavioural skills in order for them to access the curriculum: This needs to be viewed as an expectation, rather than a 
challenge. Responses to statements surrounding the role of the classroom teachers highlight individual beliefs about what constitutes education in the inclusive classroom.

The contrast in beliefs was apparent, as those who reported successes often described having more than one student with an exceptionality within their class group, but went on to describe various strategies they had utilized that resulted in improved whole-class learning. In challenging situations, having more than one student with an exceptionality appeared to leave many pre-service teachers feeling overwhelmed. Challenging situations led participants to question their ability to teach the whole class while meeting the academic needs of those with exceptionalities. One other striking contrast lay in the use of other school adults; within situations that were regarded to be successful this appeared to be an acceptable source of support. However, within challenging situations it appeared to be perceived as an inability to "solve the problem" independently and appeared to be a "last resort."

Many participants expressed concern and challenge regarding their ability to authentically extend the learning experience of students considered gifted. Research supports this finding, citing several reasons, including a lack of knowledge to modify content, the time required to modify the curriculum, difficulty in finding appropriate resources, and attitudinal barriers. VanTassel-Baska and Stambaugh (2005) claimed that there are several reasons for these barriers and that these challenges may be consistent across all types of exceptionalities. When describing challenges related to students considered gifted, it may be as useful to note what participants did not say in comparison to what they did say for other identified exceptionalities. Participants did not cite time taken away from the rest of the class as a concern. Further, when they had spent time acquiring additional resources, they did not mention concerns regarding the time spent doing so, and only rarely mentioned seeking advice from other school adults. This appears to speak to a distinct and uniform difference in the perception of meeting the needs of students considered gifted. Teacher preparation programs should provide knowledge and strategies so pre-service teachers can authentically challenge all students, including those considered gifted, in the general education classroom.

\section{Relationships}

Participants often used a range of strategies to develop positive relationships with students. Of particular interest were situations that may initially have been considered challenging. In these instances, participants described taking the time to converse with students as a means of developing a connection. In some circumstances, pre-service teachers utilized resultant knowledge of student interests to modify materials or delivery to increase engagement and interest. On other occasions, discussions with students enabled both parties to identify mutually agreeable strategies that supported the student with behaviour management, thereby increasing their engagement or supporting selfregulation of behaviour. Others reported that students appeared to respond positively simply because they felt someone had listened. Pre-service teachers in this study considered developing positive relationships as a significant means to support positive student outcomes, which is in keeping with the research. Student-teacher relationships may be even more important for students who are considered at risk due to disadvantaged 
economic backgrounds or for those with learning difficulties (Roorda, Koomen, Spilt, \& Oort, 2011).

\section{Other School Adults as Resources}

Interactions with other school adults as resources were apparent across both success and challenge situations, and descriptions of these interactions provided valuable insight into the experiences gained during practicum placements. Some descriptions contained details of other school adults providing excellent support through direct action, by providing strategies or further sources of information. The data also showed positive interactions with educational assistants, learning resource staff, and, on occasion, school principals, with participants describing staff as "amazing" and "so supportive." Educational assistants were referenced as a source of additional information or strategies, and pre-service teachers described instances of collaboration with the educational assistants to enhance student outcomes. This ability to form positive working relationships and establish mutual professional respect indicates that many of these preservice teachers were able and willing to turn to additional adults working within the classroom as resources. This finding is in contrast to that of Brackenreed and Barnett (2006) who found that, even in the first few years of their careers, teachers were resistant to having other professionals in the room. This finding may indicate that collaborative working practices are somehow deemed more acceptable during practica, as there is an acceptance that this is a learning experiences and the expectation of other adults in the room already exists. On the other hand, this could speak to a gradual change in perspective among pre-service teachers, who now more readily accept concepts such as professional collaboration and co-teaching.

Pre-service teachers reported students whom the regular teacher explicitly or implicitly appeared to have "written off" with mixed outcomes. In some situations, this led to increased feelings of efficacy as the pre-service teacher felt they had succeeded where perhaps the class teacher had less success. In other circumstances, the pre-service teacher described situations in which they, too, appear to have reduced their efforts or felt that they were unable to make any difference in the situation. This demonstrates the significance of classroom teachers in the developing beliefs and practices of pre-service teachers. The impact of these experiences cannot be overstated, as classroom teachers can be more influential than university course work in areas such as teaching practice, planning, and behaviour management (Landrum, Cook, Tankersley, \& Fitzgerald, 2002); and pre-service teachers generally perceive their practicum experiences as a means of developing their own professional practice (Conderman, Johnston-Rodriguez, Hartman, \& Walker, 2013).

\section{Limitations of Study and Recommendations for Future Research}

The qualitative data presented in this study contains a "snapshot" of pre-service teachers at the end of their initial teacher education program. Efficacy may change over time, which warrants further study. Respondents were Canadian pre-service teachers, and while many of the findings may hold true in an international context, wider implications for interpretation of the data cannot be made. There appears to be very little research on 
teacher practicum relative to teaching in diverse classrooms. Future studies should examine demographic data, attitudes, and beliefs, as well as personal or professional experiences, which may have influenced the descriptions provided by respondents. Information regarding the duration and content of courses held by each individual university did not form part of this analysis, but may be shown to be influential in the development of efficacious and inclusive beliefs. This area also warrants further research.

\section{Conclusion}

This study examined the ways in which the experiences gained during practica influence the development of efficacy of Canadian pre-service teachers in relation to teaching in inclusive classrooms. As revealed through an examination of pre-service teachers' expressed challenges and successes on practica, elements influencing feelings of challenges and successes included behaviour management, academics, relationships with students, and other school adults as resources, which in turn, influenced pre-service teacher efficacy.

The elements influencing the professional efficacy of pre-service teachers as they prepare for the work place are closely and complexly interwoven. The findings were in keeping with Bandura's (1977) theories of self-efficacy, in that perceptions of success and challenge were related to the individual's beliefs about their ability to effectively implement successful strategies and their perceptions of the subsequent outcomes for the students. Judgements regarding the effectiveness of strategies and the validity of outcomes may stem from personal beliefs about inclusion. These beliefs may be influenced by theoretical knowledge of specific exceptionalities and effective strategies. In keeping with the knowledge base on teacher efficacy, classroom management is a prominent element of attaining and maintaining efficacious beliefs; and practica in inclusive settings can increase teacher efficacy surrounding classroom management (Sokal et al., 2013). Preservice teachers who were able to implement successful solutions for managing behavioural challenges reported feelings of success in their instructional role. This was true for other key elements that appear to underlie teacher efficacy, such as academic strategies, the ability to utilize resources effectively, and forming positive relationships with students or other school adults. The data showed that challenging situations did not necessarily leave the participant feeling unsuccessful: Some participants utilized many of the same strategies and resources, but felt the situation was not resolved, and this challenged their self-efficacy. This raises concerns regarding the expectations some teachers may hold about their professional experiences and their role as a classroom teacher. Our analysis reveals that some teachers in this study may have had beliefs that were not conducive to the tenets of inclusion, which was illustrated by their concern that supporting a student's behaviour and emotional regulation takes away from academic instruction. In contrast, those who viewed students with exceptionalities as an expected part of the regular education classroom appeared better equipped to bring about positive outcomes, as they were invested in trying multiple strategies and forming positive student-teacher relationships. Practicum experiences in which pre-service teachers do not have positive experiences with students with exceptionalities may cause them to question their belief in inclusion as well as their role as classroom teachers. These concerns can be further affected by the ethos of the school, and, in particular, the beliefs of the regular 
classroom teacher. The data illustrated that classroom teachers who held less positive attitudes toward students with exceptionalities sometimes influenced the pre-service teacher's classroom behaviour toward those students.

Several elements can positively influence teacher efficacy including the ability to identify and utilize instructional and personnel resources, the ability to form supportive professional relationships with other school adults, and the ability to recognize achievement as it pertains to the individual rather than prescribed norms. Even with these elements in place, efficacy can be negatively affected by the perception that the outcome was not positive. Therefore, it is the individually held beliefs of one's efficacy to teach to diversity that is pivotal in defining perceptions and attribution of success and failure. As beliefs about self-efficacy are informed by enactive mastery experiences, vicarious experiences, physiological factors, and verbal persuasion (Bandura, 1977), teacher preparation programs can foster teacher efficacy by encouraging the development of positive attitudes and equipping teachers with the skills they need.

\section{References}

Ainscow, M. (2005). Developing inclusive education systems: What are the levers for change? Journal of Educational Change, 6(2), 109-124. doi:10.1007/s10833-005-1298-4

Ainscow, M., \& Sandill, A. (2010). Developing inclusive education systems: The role of organisational cultures and leadership. International Journal of Inclusive Education, 14(4), 401-416. doi:10.1080/13603110802504903

Avramidis, E., \& Norwich, B. (2002). Teachers' attitudes towards integration / inclusion: A review of the literature. European Journal of Special Needs Education, 17(2), 129-147. doi:10.1080/08856250210129056

Bandura, A. (1977). Self-efficacy: Toward a unifying theory of behavioral change. Psychological Review, 84(2), 191-215.

Bobek, B. L. (2009). Teacher resiliency: A key to career longevity. The Clearing House, 75(4), 202205. doi:10.1080/00098650209604932

Brackenreed, D. (2008). Inclusive education: Identifying teachers' perceived stressors in inclusive classrooms. Exceptionality Education Canada, 18(3), 131-147.

Brackenreed, D., \& Barnett, J. (2006). Teacher stress and inclusion: Perceptions of pre-service teachers. Developmental Disabilities Bulletin, 34(1-2), 156-176. Retrieved from the ERIC database (Doc. EJ815716), https://eric.ed.gov

Braun, V., \& Clarke, V. (2006). Using thematic analysis in psychology. Qualitative Research in Psychology, 3, 77-101. doi:10.1191/1478088706qp063oa

Brighton, C. M. (2003). The effects of middle school teachers' beliefs on classroom practices. Journal for the Education of the Gifted, 27, 177-206. doi:10.1177/016235320302700205

Bryant, D. P., Linan-Thompson, S., Ugel, N., Hamff, A., \& Hougen, M. (2001). The effects of professional development for middle school general and special education teachers on implementation of reading strategies in inclusive content area classes. Learning Disability Quarterly, 24(4), 251-264.

Bunch, G., Lupart, J., \& Brown, M. (1997). Resistance and acceptance: Educator attitudes to inclusion of students with disabilities (Report). Retrieved from the ERIC database (Doc. ED410713), http://eric.ed.gov 
Caprara, G. V., Barbaranelli, C., Steca, P., \& Malone, P. S. (2006). Teachers' self-efficacy beliefs as determinants of job satisfaction and students' academic achievement: A study at the school level. Journal of School Psychology, 44(6), 473-490. doi:10.1016/j.jsp.2006.09.001

Conderman, G., Johnston-Rodriguez, S., Hartman, P., \& Walker, D. (2013). Honoring voices from beginning special educators for making changes in teacher preparation. Teacher Education and Special Education, 36(1), 65-76. doi:10.1177/0888406412473311

de Boer, A., Pijl, S.J., \& Minnaert, A. (2010). Regular primary schoolteachers' attitudes towards inclusive education: A review of the literature. International Journal of Inclusive Education, 15, 331-353, doi:10.1080/13603110903030089

Edmunds, A. L., Macmillan, R. B., Specht, J., Nowicki, E. A., \& Edmunds, G. (2009). Principals and inclusive schools: Insight into practice. Education, 20(1), 1-23.

Farrell, P., Dyson, A., Polat, F., Hutcheson, G., \& Gallannaugh, F. (2007). Inclusion and achievement in mainstream schools. European Journal of Special Needs Education. doi:10.1080/08856250701267808

Forlin, C., \& Chambers, D. (2011). Teacher preparation for inclusive education: Increasing knowledge but raising concerns. Asia-Pacific Journal of Teacher Education, 39(1), 17-32. doi:10.1080/1359866X.2010.540850

Forlin, C., Keen, M., \& Barrett, E. (2008). The concerns of mainstream teachers: Coping with inclusivity in an Australian context. International Journal of Disability, Development and Education, 55(3), 251-264. doi:10.1080/10349120802268396

Friedman, I. A. (2000). Burnout in teachers: Shattered dreams of impeccable professional performance. Journal of Clinical Psychology, 56(5), 595-606.

Glazzard, J. (2011). Perceptions of the barriers to effective inclusion in one primary school: Voices of teachers and teaching assistants. Support for Learning, 26(2), 56-63. doi:10.1111/j.14679604.2011.01478.x

Hallam, S. (2009). An evaluation of the Social and Emotional Aspects of Learning (SEAL) programme: Promoting positive behaviour, effective learning and well-being in primary school children. Oxford Review of Education, 35(3), 313-330. doi:10.1080/03054980902934597

Høigaard, R., Giske, R., \& Sundsli, K. (2012). Newly qualified teachers' work engagement and teacher efficacy influences on job satisfaction, burnout, and the intention to quit. European Journal of Teacher Education, 35(3), 347-357. doi:10.1080/02619768.2011.633993

Hoy, A. W., \& Spero, R. B. (2005). Changes in teacher efficacy during the early years of teaching: A comparison of four measures. Teaching and Teacher Education, 21(4), 343-356.

Jordan, A., Schwartz, E., \& McGhie-Richmond, D. (2009). Preparing teachers for inclusive classrooms. Teaching and Teacher Education, 25(4), 535-542. doi:10.1016/j.tate.2009.02.010

Jordan, A., \& Stanovich, P. (2003). Teachers' personal epistemological beliefs about students with disabilities as indicators of effective teaching practices. Journal of Research in Special Educational Needs, 3(1). doi:10.1111/j.1471-3802.2003.00184.x

Kim, J. (2011). Influence of teacher preparation programmes on preservice teachers' attitutes toward inclusion. International Journal of Incluisve Education, 13(3), 355-377. doi:10.1080/13603110903030097

Klassen, R. M., \& Durksen, T. L. (2014). Weekly self-efficacy and work stress during the teaching practicum: A mixed methods study. Learning and Instruction, 33, 158-169. doi:10.1016/j.learninstruc.2014.05.003 
Klassen, R., Wilson, E., Siu, A. F. Y., Hannok, W., Wong, M. W., Wongsri, N., ... Jansem, A. (2013). Preservice teachers' work stress, self-efficacy, and occupational commitment in four countries. European Journal of Psychology of Education, 28(4), 1289-1309. doi:10.1007/s10212-012-0166-x

Kosko, K. W., \& Wilkins, J. L. M. (2009). General eductors' in-service training and their selfperceived ability to adapt instruction for students with IEPs. The Professional Educator, 33(2), 1-10.

Landrum, T. J., Cook, B. G., Tankersley, M., \& Fitzgerald, S. (2002). Teacher perceptions of the trustworthiness, usability, and accessibility of information from different sources. Remedial and Special Education, 23(1), 42-48. doi:10.1177/074193250202300106

Loreman, T. (2007). Seven pillars of support for inclusive education. International Journal of Whole Schooling, 3(2), 22-38.

Loreman, T., Sharma, U., \& Forlin, C. (2013). Do pre-service teachers feel ready to teach in inclusive classrooms? A four country study of teaching self-efficacy. Australian Journal of Teacher Education, 38(1), 27-44. doi:10.14221/ajte.2013v38n1.10

McGhie-Richmond, D., Irvine, A., Loreman, T., Cizman, J. L., \& Lupart, J. (2013). Teacher perspectives on inclusive education in rural Alberta, Canada. Canadian Journal of Education, $36,195-239$.

McLeskey, J., \& Waldron, N. L. (2002). Professional development and inclusive schools: Reflections on effective practice. The Teacher Educator, 37(3), 159-172.

McLeskey, J., Waldron, N. L., Spooner, F., \& Algozzine, B. (2014). Handbook of effective inclusive schools: Research and practice. New York, NY: Routledge.

Neuendorf, K. A. (2002). The content analysis guidebook. Thousand Oaks, CA: SAGE Publications.

O'Toole, C., \& Burke, N. (2013). Ready, willing and able? Attitudes and concerns in relation to inclusion amongst a cohort of Irish pre-service teachers. European Journal of Special Needs Education, 28(3), 239-253. doi:10.1080/08856257.2013.768451

Palmer, D. (2006). Durability of changes in self-efficacy of preservice primary teachers. International Journal of Science Education, 28(6), 655-671. doi:10.1080/09500690500404599

Polirstok, S. (2015). Classroom management in inclusive classrooms. Creative Education, 6, 927-933.

Richardson, V. (1996). The role of attitutes and beliefs in learning to teach. In J. Sikula (Ed.), Handbook of research on teacher education (pp. 102-119). New York, NY: Simon \& Schuster Macmillan.

Roorda, D. L., Koomen, H. M. Y., Spilt, J. L., \& Oort, F. J. (2011). The influence of affective teacherstudent relationships on students' school engagement and achievement: A meta-analytic approach. Review of Educational Research, 81(4), 493-529. doi:10.3102/0034654311421793

Ryndak, D. L., Jackson, L., \& Billingsley, F. (2000). Defining school inclusion for students with moderate to severe disabilities: What do experts say? Exceptionality, 8(2), 101-116. doi:10.1207/S15327035EX0802_2

Savage, R. (2006). Effective early reading instruction and inclusion: Some reflections on mutual dependence. International Journal of Inclusive Education, 10(4-5), 347-361. doi:10.1080/13603110500221495

Schmidt, R. J., Rozendal, M. S., \& Greenman, G. G. (2002). Reading instruction in the inclusion classroom: Research-based practices. Remedial and Special Education, 23(3), 130-140. doi:10.1177/07419325020230030101 
Sharma, U., Forlin, C., \& Loreman, T. (2008). Impact of training on pre-service teachers' attitudes and concerns about inclusive education and sentiments about persons with disabilities. Disability \& Society, 23(7), 773-785. doi:10.1080/09687590802469271

Sharma, U., Forlin, C., Loreman, T., \& Earle, C. (2006). Pre-service teachers' attitudes, concerns and sentiments about inclusive education: An international comparison of novice pre-service teachers. International Journal of Special Education, 21(2), 80-93. Retrieved from the ERIC database (Doc. EJ843609), https://eric.ed.gov

Smith, D. D., \& Tyler, N. C. (2011). Effective inclusive education: Equipping education professionals with necessary skills and knowledge. Prospects, 41(3), 323-339. doi:10.1007/s11125-0119207-5

Sokal, L., Woloshyn, D., \& Funk-Unrau, S. (2013). How important is practicum to pre-service teacher development for inclusive teaching? Effects on efficacy in classroom management. Alberta Journal of Educational Research, 59(2), 285-298.

Specht, J., McGhie-Richmond, D., Loreman, T., Mirenda, P., Bennett, S., Gallagher, T., ... Cloutier, S. (2016). Teaching in inclusive classrooms: Efficacy and beliefs of Canadian preservice teachers. International Journal of Inclusive Education, 20(1), 1-15. doi:10.1080/13603116.2015.1059501

Stanovich, P., \& Jordan, A. (2004). The beliefs and practices of Canadian teachers about including students with special needs in their regular elementary classrooms. Exceptionality Education Canada, 14, 25-46.

UNESCO. (1994). The Salamanca statement and framework for action on special needs education. Paris, France: Author. Retrieved from the UNESCO website, http://www.unesco.org/education/pdf /SALAMA_E.PDF

UNESCO. (1999). Salamanca five years on: A review of UNESCO activities in the light of The Salamanca Statement and Framework for Action. Paris, France: Author. Retrieved from the UNESCO website, http://unesdoc.unesco.org/images/0011/001181/118118eo.pdf

VanTassel-Baska, J., \& Stambaugh, T. (2005). Challenges and possibilities for serving gifted learners in the regular classroom. Theory Into Practice, 44(3), 211-217. doi:10.1207/s15430421tip4403_5

Woolfolk Hoy, A., \& Burke-Spero, R. (2005). Changes in teacher efficacy during the early years of teaching: A comparison of four measures. Teaching and Teacher Education, 21(4), 343-356.

\section{Authors' Note}

This research was supported by SSHRC grant 435-2015-0128.

Correspondence concerning this article should be addressed to Gabrielle Young, Faculty of Education, Memorial University of Newfoundland, G. A. Hickman Building, Box 125, St. John's, NL, A1B 3X8, Canada. Email: gabrielle.young@mun.ca 